\title{
Oatmeal porridge: impact on microflora-associated characteristics in healthy subjects
}

\author{
Jørgen Valeur ${ }^{1 *}$, Nathalie G. Puaschitz ${ }^{2}$, Tore Midtvedt ${ }^{3}$ and Arnold Berstad ${ }^{1}$ \\ ${ }^{1}$ Unger-Vetlesen Institute, Lovisenberg Diaconal Hospital, Oslo NO-0440, Norway \\ ${ }^{2}$ Department of Clinical Science, University of Bergen, Bergen NO-5021, Norway \\ ${ }^{3}$ Department of Microbiology, Tumor and Cell Biology, Karolinska Institutet, Stockholm SE-171 77, Sweden
}

(Submitted 22 July 2015 - Final revision received 17 September 2015 - Accepted 24 September 2015 - First published online 29 October 2015)

\section{Abstract}

Oatmeal porridge has been consumed for centuries and has several health benefits. We aimed to investigate the effect of oatmeal porridge on gut microflora functions. A total of ten healthy subjects ingested $60 \mathrm{~g}$ oatmeal porridge daily for $1 \mathrm{week}$. The following microflora-associated characteristics were assessed before and after the intervention: intestinal gas production following lactulose ingestion, faecal excretion of SCFA and faecal levels of urease and $\beta$-galactosidase. In addition, rectal levels of $\mathrm{PGE}_{2}$ were measured. Microbial fermentation as evaluated by intestinal gas production and excretion of SCFA did not change significantly following the dietary intervention. However, faecal levels of $\beta$-galactosidase and urease decreased after eating oatmeal porridge $(P=0.049$ and 0.031 , respectively). Host inflammatory state, as measured by rectal levels of $\mathrm{PGE}_{2}$, also decreased, but the change was not significant $(P=0 \cdot 168)$. The results suggest that oatmeal porridge has an effect on gut microbial functions and may possess potential prebiotic properties that deserve to be investigated further.

\section{Key words: $\beta$-Galactosidase: Hydrogen: Methane: Microbiota: PGE $_{2}$ : SCFA: Urease}

Oats have been cultivated since prehistoric times, and oatmeal porridge is a traditional dish in several North European countries ${ }^{(1)}$. Anecdotically, Samuel Johnson (1709-1784) defined oat as 'a grain, which in England is generally given to horses, but in Scotland supports the people' - whereupon Patrick Murray, 5th Lord Elibank (1703-1778), replied: 'Yes, and where else will you see such horses and such men?' (cited by Fitzsimmons ${ }^{(2)}$ ). Indeed, consumption of oats has several health benefits ${ }^{(3)}$. A role of oat $\beta$-glucans in prevention of the metabolic syndrome has been established $^{(4)}$, and oats may protect against both organic diseases and functional disorders affecting the gastrointestinal tract ${ }^{(5)}$. In vitro fermentation studies ${ }^{(6)}$, and in vivo animal studies ${ }^{(7,8)}$, suggest that certain constituents of oats may influence the gut microbiota. However, as recently emphasised by Rose ${ }^{(9)}$, the impact of eating wholegrain oats, containing dietary fibres, lipids and phenolics in a unique combination, has been sparsely studied on man.

The gut microbial community can be evaluated either by assessing its composition or by measuring its functions. The term 'microflora-associated characteristic' (MAC) has been introduced to designate the latter approach, being defined as the recording of any anatomical structure or physiological, biochemical, or immunological function in a macroorganism, which has been influenced by the microflora in either an anabolic or catabolic way $^{(10)}$. In the present pilot study, we aimed to explore the effect of eating oatmeal porridge every day for 1 week on healthy subjects by assessing the following MAC: lactulose-induced intestinal gas production, faecal excretion of SCFA and faecal levels of $\beta$-galactosidase and urease. In addition, rectal levels of $\mathrm{PGE}_{2}$ were analysed, as a measure of host inflammatory state.

\section{Methods}

\section{Subjects}

Healthy subjects were recruited from the hospital staff at Haukeland University Hospital (Bergen, Norway) and from students at the University of Bergen (Bergen, Norway). They were included if they considered themselves to be healthy, did not use any medications and were not pregnant. The participants were not further medically examined, but they were excluded if they fulfilled the Rome III criteria for irritable bowel syndrome $^{(11)}$ or had used antibiotics during the past month. This study was conducted according to the guidelines laid down in the Declaration of Helsinki, and all procedures involving human subjects were approved by the Regional Committee for Medical Research Ethics (REK Vest no. 030.08) and the Norwegian Social Science Data Service (no. 18685). Written informed consent was obtained from all subjects.

\section{Dietary intervention}

The subjects were instructed to avoid eating products containing oats for 2 weeks before the study, but otherwise maintained their 
habitual diet throughout the study period. For $7 \mathrm{~d}$ they ingested a daily portion of oatmeal porridge, made from $60 \mathrm{~g}$ oatmeal (1573 kJ/100 g (376 kcal/100 g); 'AXA Bjørn Store Havregryn'; Lantmännen Cerealia), boiled with $150 \mathrm{ml}$ tap water. The oatmeal contained (per $100 \mathrm{~g}$ ) $13 \mathrm{~g}$ protein, $7 \mathrm{~g}$ fat, $61 \mathrm{~g}$ carbohydrate and $8.5 \mathrm{~g}$ dietary fibre, including $4.7 \mathrm{~g} \beta$-glucans. Adherence to the dietary intervention was documented on a Norwegian diary that the participants were required to fill in.

\section{Assessment of lactulose-induced intestinal gas production}

The subjects underwent a lactulose breath test at the day before and the day after the dietary intervention. They were asked not to take any food or drink for $10 \mathrm{~h}$ before the challenge and not to use tobacco, eat, drink, sleep or walk around during the test. At 08.30 hours, baseline breath samples were collected, and the subjects ingested a solution of $10 \mathrm{~g}$ lactulose dissolved in $120 \mathrm{ml}$ tap water, immediately followed by $60 \mathrm{ml}$ of pure tap water for mouth cleaning. Breath sampling was then performed using collection bags from QuinTron Instrument Company at every $15 \mathrm{~min}$ for $3 \mathrm{~h}$ following lactulose ingestion. Pulmonary excretion of $\mathrm{H}_{2}$ and methane was quantified after correction for alveolar quality, based on $\mathrm{CO}_{2}$ concentration, using a QuinTron Model SC Gas Chromatograph (QuinTron Instrument Company). Individuals with methane excretion $>1$ parts per million (ppm) above the atmospheric methane concentration (i.e. approximately $1.8 \mathrm{ppm}^{(12)}$ ) were classified as methane producers.

\section{Assessment of faecal levels of SCFA, $\beta$-galactosidase and urease}

Faecal samples were collected before and after the dietary intervention. The subjects collected all faeces that passed during a 72-h period, using one plastic box per d (volume $1000 \mathrm{ml}$; diameter $133 \mathrm{~mm}$; reg. codes 257077 and 257078; Corporate Express). The upper edge of these boxes was equipped with a rim, making it easy to hold the box with both hands while defaecating directly into it. The subjects were carefully instructed on how this procedure to be performed and were told to store the boxes at $-20^{\circ} \mathrm{C}$ immediately after voiding faeces and bring the frozen boxes to the hospital. Total $(72 \mathrm{~h})$ faecal wet weight was noted, and the collected faeces was homogenised with distilled water at a volume corresponding to two times the faecal wet weight and stored at $-20^{\circ} \mathrm{C}$ until analysis of SCFA, $\beta$-galactosidase and urease.

SCFA analyses were performed at Karolinska Institutet (Stockholm, Sweden). The faecal material was homogenised after addition of distilled water containing $3 \mathrm{mmol} / \mathrm{l}$ of 2-ethylbutyric acid (as internal standard) and $0.5 \mathrm{mmol} / \mathrm{l}$ of $\mathrm{H}_{2} \mathrm{SO}_{4} ; 2 \mathrm{ml}$ of the homogenate was vacuum distilled, according to the method of Zijlstra et $a l .{ }^{(13)}$, as modified by Høverstad et $a l^{(14)}$. The distillate was analysed with GLC and quantified using internal standardisation. Flame ionisation detection was employed. The results were expressed in $\mathrm{mmol} / \mathrm{kg}$ wet weight. The following SCFA were analysed: acetic, propionic, iso-butyric, $n$-butyric, iso-valeric, $n$-valeric, isocaproic and $n$-caproic acids. Excretions of individual SCFA were calculated by multiplying the concentrations with the diluted $72 \mathrm{~h}$ faecal wet weight. Proportions of individual SCFA were calculated as percentages of total SCFA. On the basis of the work of Tjellström et $a l^{(15)}$, we calculated two fermentation indices as follows: fermentation index A, reflecting the fermentation of carbohydrates and conceivably the pro-inflammatory properties of SCFA, was calculated as acetic acid concentrations minus propionic and butyric acid concentrations divided by the total concentration of SCFA. Fermentation index B, reflecting the fermentation of proteins and conceivably the anti-inflammatory properties of SCFA, was calculated as the sum of iso-butyric and iso-valeric acids.

Analysis of $\beta$-galactosidase was performed in the prehomogenised samples that were diluted and homogenised once more with distilled water at a volume corresponding to eight times the original faecal wet weight. After this second homogenisation, a detergent (Triton X-100; CAS reg. no. 9002-93-1; Sigma-Aldrich) was added to the solution at $1 \%$ concentration, and the samples were homogenised once more. Enzyme activity was then assayed fluorimetrically from the supernatants as described by Peters et al. ${ }^{(16)}$ and modified by Andersen et $a l^{(17)}$.

Analysis of urease was performed in the pre-homogenised samples by a modified 'rapid urease test' ${ }^{\text {(18) }}$, principally similar to the routine clinical test used to detect the presence of Helicobacter pylori in gastric mucosal biopsies. Briefly, a working substrate solution was made from $0.1 \mathrm{ml} 42 \mathrm{~mm}-\mathrm{HCl}$ and $20 \mathrm{ml}$ of a solution containing $2 \mathrm{~g}$ urea, $20 \mathrm{ml}$ distilled water and 10 drops of fenol red. Homogenised faeces of $10 \mu$ (diluted 1:8 with distilled water) was added to $200 \mathrm{ml}$ of this working solution, and the time to colour change into red was noted. A standard curve, developed at the University of Bergen and based on Jack bean urease measurements, was then used to convert the time to colour change into urease concentration in $\mathrm{mg} / \mathrm{ml}$.

\section{Assessment of rectal levels of $P G E_{2}$}

Rectal dialysis was performed in continuation with the lactulose breath test before and after the dietary intervention. After finishing the 3-h breath sampling period, the subjects were offered a 30 min lunch break. Taking advantage that food intake triggers the gastrocolic reflex, the subjects were asked to evacuate their bowels completely during this lunch period. Rectal dialyses were then performed for $4 \mathrm{~h}$. The procedure has been described in detail by Egan et al. ${ }^{(19)}$. Briefly, dialysis bags $(12 \mathrm{~cm}, 4 \mathrm{ml})$ were made of cellulose membrane tubing (Visking code DVT12000.01.000; molecular weight cut-off 12-14kDa; Medicell International Ltd), filled with rheomacrodex (10\% dextran (mean molecular weight $40 \mathrm{kDa}$ ) in saline; Meda $\mathrm{A} / \mathrm{S}$ ) and inserted into the empty rectum. Dialysis bags were stored overnight at $4^{\circ} \mathrm{C}$ and bathed in rheomacrodex solution; there was no need for additional lubrication upon insertion. The dialysis bags were left for $4 \mathrm{~h}$ to obtain equilibrium with rectal fluid $^{(20)}$, and the dialysates were thereafter aspirated from the bags using a syringe and a needle, transferred into plastic vials and stored at $-80^{\circ} \mathrm{C}$ until analysis. $\mathrm{PGE}_{2}$ levels were measured using an enzyme immunoassay kit (Cat. no. 514010; Cayman Chemical Company), following the manufacturer's instructions. The intra-assay CV was $5 \cdot 6 \%$. 


\section{Statistical analyses}

Data were analysed using GraphPad Prism version 6.0 (GraphPad Software Inc.). Data are expressed as mean values and standard deviations, unless otherwise stated. We used paired $t$ tests for comparisons of means before and after the dietary intervention. All tests were two-tailed, and $P$ values $<0.05$ was considered statistically significant.

\section{Results}

\section{Subjects}

Ten healthy subjects - eight females and two males, aged 22-49 years with a mean BMI of 23.0 (SD 2.9$) \mathrm{kg} / \mathrm{m}^{2}$ - agreed to participate. All subjects completed the dietary intervention and underwent the prescribed study procedures. However, because of logistical reasons, SCFA levels were not analysed in faecal samples from one participant, and one individual refused to undergo rectal dialysis.

\section{Lactulose-induced intestinal gas production}

Neither basal nor lactulose-induced excretion of $\mathrm{H}_{2}$ changed significantly following the dietary intervention (Fig. 1(a)). Three individuals were classified as methane producers, but neither basal nor lactulose-induced excretion of methane changed significantly following the dietary intervention (Fig. 1(b)). $\mathrm{H}_{2}$ levels were similar in methane producers and methane non-producers (data not shown).

\section{Faecal levels of SCFA, $\beta$-galactosidase and urease}

Faecal wet weight $(72 \mathrm{~h})$ did not change following the dietary intervention. It varied between 90 and $666 \mathrm{~g}$ before the intervention, with a mean value of 394.5 (SD 191.4) g, and between 100 and $693 \mathrm{~g}$ after the intervention, with a mean value of $365 \cdot 1$ (sD 173.0) g.

Excretions and proportions of SCFA did not change following the dietary intervention (Table 1 ), and fermentation indices A and $\mathrm{B}$ remained unchanged ( $P=0.6$ and 0.6 , respectively).

Faecal $\beta$-galactosidase activity was reduced during the study period (Fig. 2), from 14.6 (SD 14.8) to 5.3 (SD 3.7) $\mathrm{mU} / \mathrm{ml}$ $(P=0 \cdot 049)$.

Faecal urease levels decreased from 4.5 (sD 3.0) to 3.7 (sD $2 \cdot 8) \mathrm{mg} / \mathrm{ml}(P=0.031)$ following the dietary intervention (Fig. 3).

\section{Rectal levels of $P G E_{2}$}

Concentrations of $\mathrm{PGE}_{2}$ in rectal dialysates decreased from 298.0 (sD $314 \cdot 1$ ) to $163 \cdot 1$ (sD $70 \cdot 5$ ) $\mathrm{pg} / \mathrm{ml}$ following the dietary intervention (Fig. 4). However, this reduction was not statistically significant $(P=0 \cdot 168)$.

\section{Discussion}

The present study aimed to explore the effect of oatmeal porridge on gut MAC. Microbial adaptions to dietary changes are known to occur rapidly ${ }^{(21)}$. Consistently, the results of our short dietary intervention suggest that certain microbial functions are modified within 1 week by eating oatmeal porridge. In the following, we discuss possible implications of these findings.

Microbial fermentation was evaluated both by measuring production of intestinal gas following lactulose ingestion and by assessing faecal excretion of SCFA. Lactulose is a disaccharide resistant to hydrolysis by human digestive enzymes and therefore unabsorbable within the small intestine but readily fermentable by colonic microbiota. Hence, gas excretion following lactulose ingestion may be considered as a measure of colonic

Table 1. SCFA excretion (mmol/72 h) and proportions (percentage of total SCFA) in healthy subjects ( $n$ 9) before and after eating oatmeal porridge daily for 1 week

(Mean values and standard deviations)

\begin{tabular}{|c|c|c|c|c|c|}
\hline \multirow[b]{2}{*}{ SCFA excretion (mmol/72 h) } & \multicolumn{2}{|c|}{ Before } & \multicolumn{2}{|c|}{ After } & \multirow[b]{2}{*}{$P$} \\
\hline & Mean & SD & Mean & SD & \\
\hline Acetic acid & $44 \cdot 1$ & $22 \cdot 7$ & $60 \cdot 1$ & $44 \cdot 4$ & 0.4 \\
\hline Total SCFA concentration (\%) & $75 \cdot 0$ & $6 \cdot 6$ & $76 \cdot 1$ & 4.4 & 0.4 \\
\hline Propionic acid & 4.7 & $2 \cdot 3$ & $6 \cdot 8$ & $5 \cdot 1$ & 0.3 \\
\hline Total SCFA concentration (\%) & $8 \cdot 7$ & 1.8 & 8.5 & 1.4 & 0.6 \\
\hline iso-Butyric acid & 0.8 & 0.6 & 0.9 & 0.7 & 0.7 \\
\hline Total SCFA concentration (\%) & 1.4 & 0.8 & 1.2 & 0.5 & 0.2 \\
\hline$n$-Butyric acid & $6 \cdot 7$ & $5 \cdot 2$ & $9 \cdot 6$ & $7 \cdot 7$ & 0.4 \\
\hline Total SCFA concentration (\%) & $11 \cdot 3$ & 4.2 & 11.4 & 3.6 & 0.9 \\
\hline iso-Valeric acid & $1 \cdot 1$ & 0.7 & 1.0 & 0.7 & 0.7 \\
\hline Total SCFA concentration (\%) & $2 \cdot 0$ & 1.1 & 1.5 & 0.9 & 0.1 \\
\hline$n$-Valeric acid & 0.7 & 0.4 & 0.6 & 0.3 & 0.7 \\
\hline Total SCFA concentration (\%) & 1.3 & 0.7 & 1.0 & 0.6 & 0.1 \\
\hline iso-Caproic acid & 0.0 & 0.0 & 0.0 & 0.0 & NA \\
\hline Total SCFA concentration (\%) & 0.0 & 0.0 & 0.0 & 0.0 & NA \\
\hline$n$-Caproic acid & 0.3 & 0.2 & 0.2 & $0 \cdot 1$ & 0.2 \\
\hline Total SCFA concentration (\%) & 0.4 & 0.3 & 0.3 & 0.3 & 0.002 \\
\hline Total SCFA & 58.5 & $29 \cdot 7$ & 79.0 & 57.5 & 0.4 \\
\hline
\end{tabular}

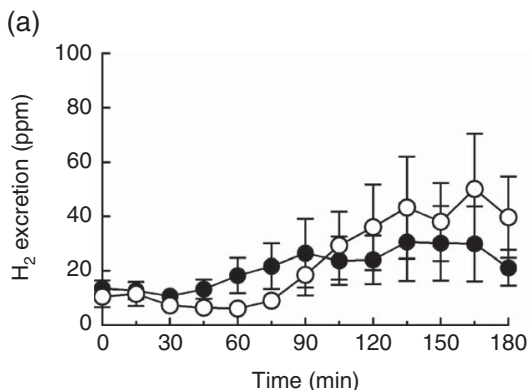

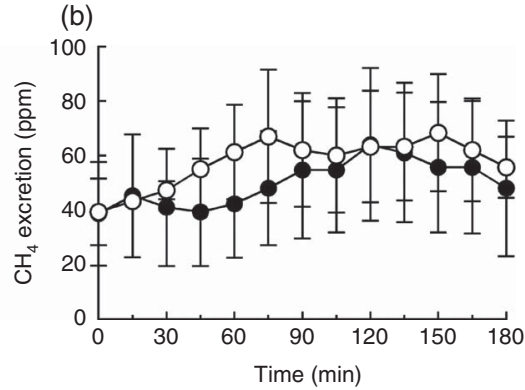

Fig. 1. Intestinal gas excretion following ingestion of a $10 \mathrm{~g}$ lactulose solution in healthy subjects ( $n$ 10) before and after eating oatmeal porridge daily for $1 \mathrm{week}$. The results are shown as mean values with error bars representing the standard errors. (a) Excretion of $\mathrm{H}_{2}$ in all subjects ( $n$ 10). (b) Excretion of methane in methaneproducing subjects $(n 3)$. $\bigcirc$, After; $\bigcirc$, before. ppm, Parts per million. 


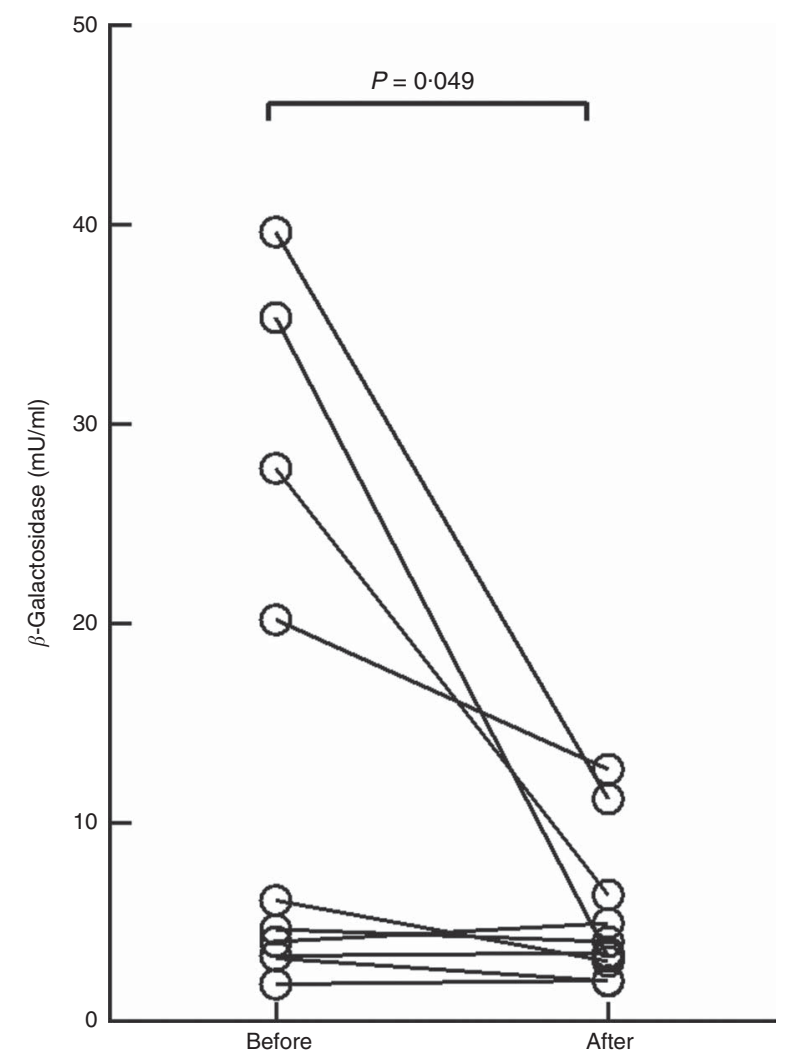

Fig. 2. Levels of $\beta$-galactosidase in faecal samples from healthy subjects $(n 10)$ before and after eating oatmeal porridge daily for 1 week.

fermentation capacity. Similar gas excretion curves before and after the dietary intervention thus suggest that eating oatmeal porridge does not alter the colonic ability to ferment carbohydrates. Regarding the effect of oat consumption on SCFA excretion, our results are comparable to previous studies by others $^{(22-24)}$. However, it should be emphasised that SCFA produced within the colon are readily absorbed, and only small amounts are excreted in the faeces. Faecal excretion of SCFA is therefore an uncertain estimate of colonic SCFA production. The pattern of gut microflora fermentation, as assessed by considering the relative distributions of individual SCFA, as well as indices of saccharolytic $v$. proteolytic fermentation ${ }^{(15)}$, may be more relevant, but neither of these parameters was changed during the present study.

$\beta$-Galactosidase is a microbial enzyme with similar catalytic activity as human lactase and is therefore often denoted as 'microbial lactase'. Measurement of this microbial function was encouraged by previous studies suggesting that induction of $\beta$-galactosidase may be associated with improvement of abdominal symptoms in individuals with lactose intolerance $^{(25,26)}$. However, increased $\beta$-galactosidase levels should probably not be considered as a general marker of a favourable gut microflora ${ }^{(27)}$, as demonstrated by our finding of decreased levels of $\beta$-galactosidase activity in faeces following oat consumption. A reasonable interpretation is that this enzyme is simply not needed by the gut microflora when eating oatmeal porridge, and hence the microbiota adapt accordingly.

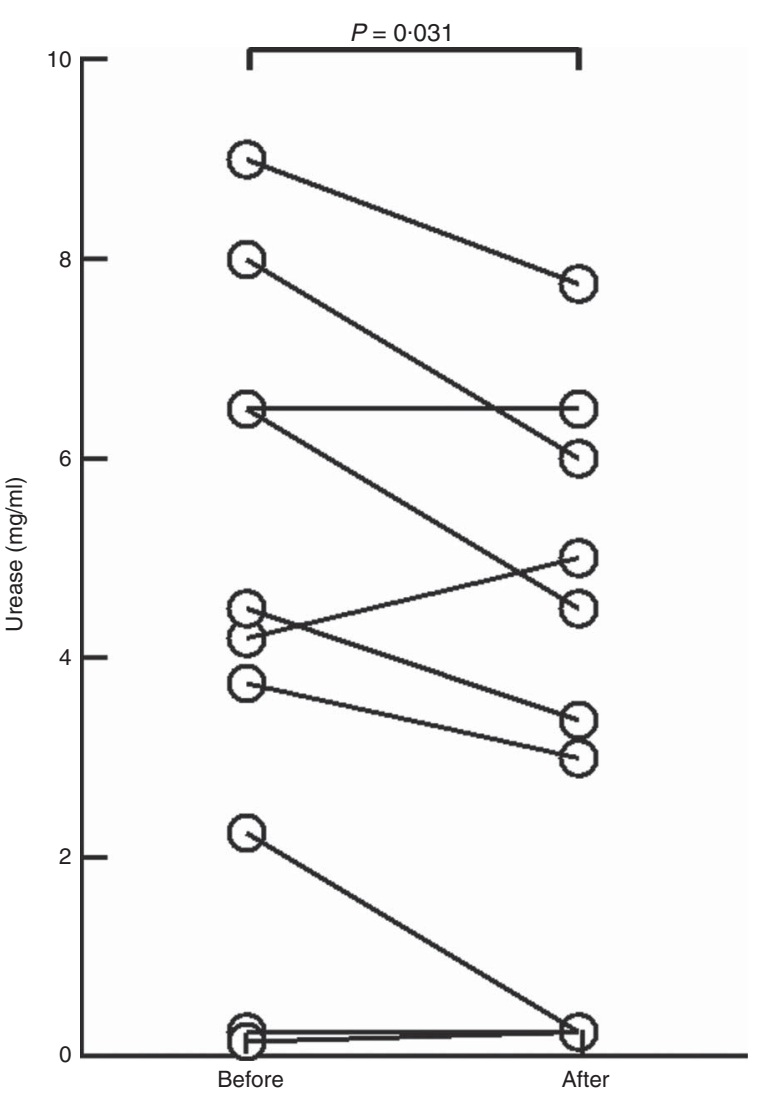

Fig. 3. Levels of urease in faecal samples from healthy subjects $(n 10)$ before and after eating oatmeal porridge daily for 1 week.

It should be emphasised, however, that faecal levels of $\beta$-galactosidase may not properly reflect levels of $\beta$-galactosidase in the proximal colon, where most of the saccharolytic activity takes place.

Urease is a microbial enzyme that catalyses the hydrolysis of urea into ammonia. Ammonia exerts several toxic effects upon the host ${ }^{(28)}$, and urease has previously been advocated as a general marker of an unfavourable gut microflora ${ }^{(27)}$. Our results of decreased faecal levels of urease following the dietary intervention are therefore interesting and suggest that oatmeal porridge has prebiotic actions. Furthermore, the use of oatmeal porridge in the treatment of hyperammonaemia, to suppress intestinal urease levels and thereby blood ammonia levels ${ }^{(29)}$, may be considered. Decreased levels of urease following ingestion of oatmeal porridge is probably a consequence of microbial adaption ${ }^{(30)}$. As for the other faecal parameters assessed in this study, the levels of urease in faeces may not properly reflect the levels throughout the gastrointestinal tract.

Oats seem to have antioxidant capacity and antiinflammatory activity ${ }^{(31)}$. The $\beta$-glucan components may be particularly important ${ }^{(32)}$, as demonstrated in a recent animal study showing positive effects of $\beta$-glucans on colonic tissue of both healthy rats and rats with lipopolysaccharideinduced enteritis ${ }^{(33)}$. In the present study, we analysed $\mathrm{PGE}_{2}$ levels of the rectum as a marker of inflammatory activity of the gastrointestinal tract. Although the levels were not significantly altered after eating oatmeal porridge, concentrations of $\mathrm{PGE}_{2}$ 


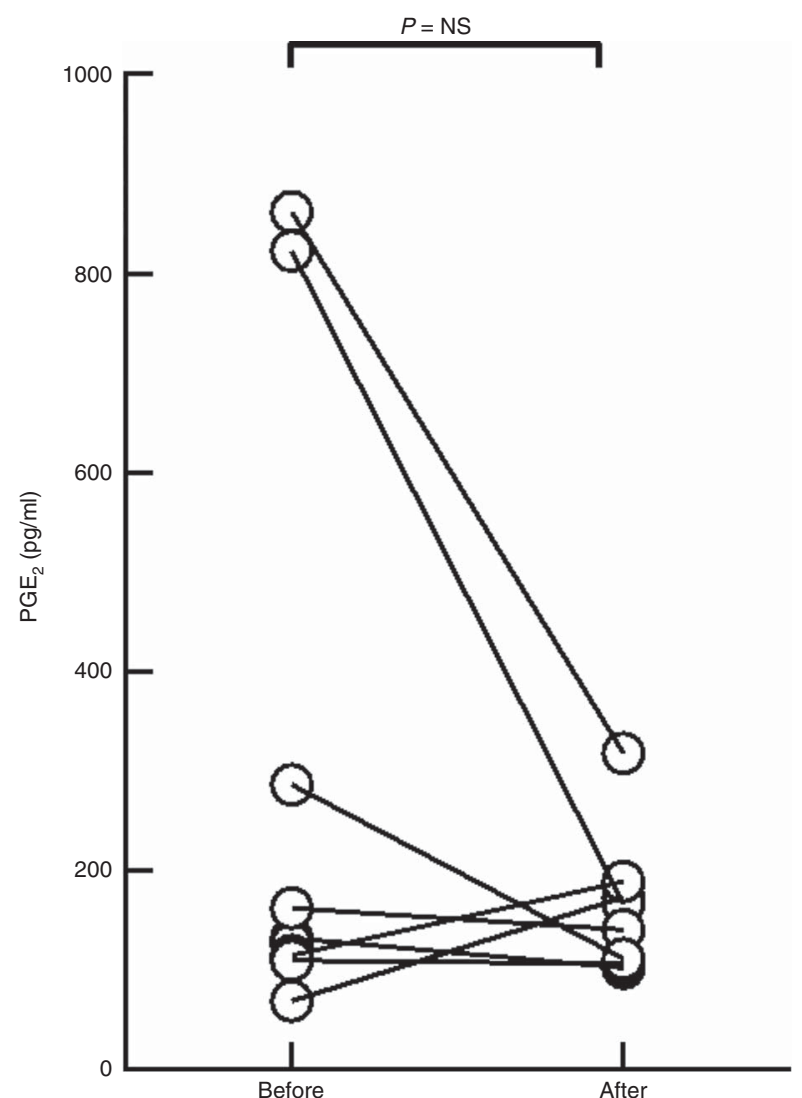

Fig. 4. Levels of $P G E_{2}$ in rectal dialysates from healthy subjects $(n$ ) before and after eating oatmeal porridge daily for 1 week.

were markedly reduced in some of the subjects. Thus, further studies on the effect of oatmeal porridge on inflammatory diseases of the colon should be encouraged, both in conditions characterised by low-grade (e.g. irritable bowel syndrome) and overt (e.g. inflammatory bowel disease) intestinal inflammation.

Taken together, ingestion of oatmeal porridge daily for 1 week in healthy subjects reduced faecal levels of $\beta$-galactosidase and urease, whereas colonic fermentation capacity, excretion of SCFA and rectal inflammation, assessed by $\mathrm{PGE}_{2}$ levels, were unaltered. The results thus suggest that oatmeal porridge may modulate gut microbial functions. These findings should encourage further studies to investigate the potential prebiotic properties of oatmeal porridge.

\section{Acknowledgements}

The authors thank Behzad Gharehnia, Tove Berstad, Elisabeth Norin and Anna-Karin Persson for invaluable technical assistance.

The study was funded by the University of Bergen, Norway.

The authors' contributions are as follows: J. V. designed the study, performed the data collection, carried out the data analyses and wrote the manuscript; N. G. P. designed the study, performed the data collection and carried out the data analyses; T. M. supervised the study and contributed to data interpretation; A. B. designed the study, supervised the study and contributed to data interpretation. All authors read and approved the final version of the manuscript.

The authors have no financial or personal conflicts of interest to declare.

\section{References}

1. Moore-Coyler RJ (1995) Oats and oat production in history and pre-history. In The Oat Crop: Production and Utilization, pp. 1-33 [RW Welch, editor]. London: Chapman \& Hall.

2. Fitzsimmons R (2012) Oh, what those oats can do. Quaker oats, the Food and Drug Administration, and the market value of scientific evidence 1984 to 2010. Compr Rev Food Sci Food Saf 11, 56-99.

3. Rasane P, Jha A, Sabikhi L, et al. (2015) Nutritional advantages of oats and opportunities for its processing as value added foods - a review. I Food Sci Technol 52, 662-675.

4. Cloetens L, Ulmius M, Johansson-Persson A, et al. (2012) Role of dietary beta-glucans in the prevention of the metabolic syndrome. Nutr Rev 70, 444-458.

5. Thies F, Masson LF, Boffetta P, et al. (2014) Oats and bowel disease: a systematic literature review. BrJ Nutr 112, Suppl. 2, S31-S43.

6. Hughes SA, Shewry PR, Gibson GR, et al. (2008) In vitro fermentation of oat and barley derived beta-glucans by human faecal microbiota. FEMS Microbiol Ecol 64, 482-493.

7. Drzikova B, Dongowski G \& Gebhardt E (2005) Dietary fibre-rich oat-based products affect serum lipids, microbiota, formation of short-chain fatty acids and steroids in rats. Br J Nutr 94, 1012-1025.

8. Snart J, Bibiloni R, Grayson T, et al. (2006) Supplementation of the diet with high-viscosity beta-glucan results in enrichment for lactobacilli in the rat cecum. Appl Environ Microbiol 72, 1925-1931.

9. Rose DJ (2014) Impact of whole grains on the gut microbiota: the next frontier for oats? Br J Nutr 112, Suppl. 2, S44-S49.

10. Midtvedt T, Björneklett A, Carlsten-Duke B, et al. (1985) The influence of antibiotics upon microflora associated characteristics in man and animals. In Germfree Research; Microflora Control and Its Application to the Biochemical Sciences. Progress in Clinical and Biological Research, vol. 181, pp. 241-244 [BS Wostman, editor]. New York: Alan R. Liss Corporation.

11. Longstreth GF, Thompson WG, Chey WD, et al. (2006) Functional bowel disorders. Gastroenterology 130, 1480-1491.

12. Levitt MD, Furne JK, Kuskowski M, et al. (2006) Stability of human methanogenic flora over 35 years and a review of insights obtained from breath methane measurements. Clin Gastroenterol Hepatol 4, 123-129.

13. Zijlstra JB, Beukema J, Wolthers BG, et al. (1977) Pretreatment methods prior to gaschromatographic analysis of volatile fatty acids from faecal samples. Clin Chim Acta 78, 243-250.

14. Høverstad T, Fausa O, Bjørneklett A, et al. (1984) Short-chain fatty acids in the normal human feces. Scand J Gastroenterol 19, 375-381.

15. Tjellström B, Högberg L, Stenhammar L, et al. (2012) Effect of exclusive enteral nutrition on gut microflora function in children with Crohn's disease. Scand J Gastroenterol 47, 1454-1459.

16. Peters TJ, Heath JR, Wansbrough-Jones MH, et al. (1975) Enzyme activities and properties of lysosomes and brush borders in jejunal biopsies from control subjects and patients with coeliac disease. Clin Sci Mol Med $\mathbf{4 8}$, 259-267. 
17. Andersen KJ, Schjonsby H \& Skagen DW (1983) Enzyme activities in human and rat jejunal mucosa. Scand J Gastroenterol 18, 241-249.

18. Nysaeter G, Berstad K, Weberg R, et al. (1992) [Diagnosis of Helicobacter pylori infection. Rapid urease test, microscopy of smears and culture from ventricular biopsy compared with the 14C-urea breath test]. Tidsskr Nor Laegeforen $\mathbf{1 1 2}$, 2356-2358.

19. Egan LJ, Sandborn WJ, Mays DC, et al. (1998) Dialysis of the rectum for sampling drug concentrations in the luminal extracellular fluid of the gut: technique and precision. Aliment Pharmacol Ther 12, 679-684.

20. Lauritsen K, Laursen LS, Bukhave K, et al. (1986) Effects of topical 5-aminosalicylic acid and prednisolone on prostaglandin E2 and leukotriene B4 levels determined by equilibrium in vivo dialysis of rectum in relapsing ulcerative colitis. Gastroenterology $91,837-844$.

21. David LA, Maurice CF, Carmody RN, et al. (2014) Diet rapidly and reproducibly alters the human gut microbiome. Nature $\mathbf{5 0 5}, 559-563$.

22. Kashtan H, Stern HS, Jenkins DJ, et al. (1992) Colonic fermentation and markers of colorectal-cancer risk. Am J Clin Nutr 55, 723-728.

23. Hallert C, Bjorck I, Nyman M, et al. (2003) Increasing fecal butyrate in ulcerative colitis patients by diet: controlled pilot study. Inflamm Bowel Dis 9, 116-121.

24. Noakes M, Clifton PM, Nestel PJ, et al. (1996) Effect of high-amylose starch and oat bran on metabolic variables and bowel function in subjects with hypertriglyceridemia. $A m J$ Clin Nutr 64, 944-951.
25. Hertzler SR \& Savaiano DA (1996) Colonic adaptation to daily lactose feeding in lactose maldigesters reduces lactose intolerance. Am J Clin Nutr 64, 232-236.

26. Szilagyi A, Rivard J \& Fokeeff K (2001) Improved parameters of lactose maldigestion using lactulose. Dig Dis Sci $\mathbf{4 6}$, 1509-1519.

27. Brigidi P, Vitali B, Swennen E, et al. (2001) Effects of probiotic administration upon the composition and enzymatic activity of human fecal microbiota in patients with irritable bowel syndrome or functional diarrhea. Res Microbiol 152, 735-741.

28. Mobley HL \& Hausinger RP (1989) Microbial ureases: significance, regulation, and molecular characterization. Microbiol Rev 53, 85-108.

29. Shen TC, Albenberg L, Bittinger K, et al. (2015) Engineering the gut microbiota to treat hyperammonemia. J Clin Invest 125, 2841-2850.

30. Langran M, Moran BJ, Murphy JL, et al. (1992) Adaptation to a diet low in protein: effect of complex carbohydrate upon urea kinetics in normal man. Clin Sci (Lond) 82, 191-198.

31. Chu YF, Wise ML, Gulvady AA, et al. (2013) In vitro antioxidant capacity and anti-inflammatory activity of seven common oats. Food Chem 139, 426-431.

32. Raa J (2015) Immune modulation by non-digestible and non-absorbable beta-1,3/1,6-glucan. Microb Ecol Health Dis 26, 27824

33. Wilczak J, Blaszczyk K, Kamola D, et al. (2015) The effect of low or high molecular weight oat beta-glucans on the inflammatory and oxidative stress status in the colon of rats with LPS-induced enteritis. Food Funct 6, 590-603. 